\title{
Locoregional and Distant Recurrence Patterns in Young versus Elderly Women Treated for Breast Cancer
}

\author{
Soumon Rudra, David S. Yu, Esther S. Yu, Jeffrey M. Switchenko, \\ Donna Mister, and Mylin A. Torres \\ Department of Radiation Oncology, Winship Cancer Institute, Emory University School of Medicine, Atlanta, GA 30322, USA \\ Correspondence should be addressed to Mylin A. Torres; matorre@emory.edu
}

Received 15 January 2015; Revised 29 March 2015; Accepted 29 March 2015

Academic Editor: Ian S. Fentiman

Copyright (c) 2015 Soumon Rudra et al. This is an open access article distributed under the Creative Commons Attribution License, which permits unrestricted use, distribution, and reproduction in any medium, provided the original work is properly cited.

\begin{abstract}
Objective. This study examined recurrence patterns in breast cancer patients younger than age of 40 and older than age of 75, two groups that are underrepresented in clinical trials and not routinely screened by mammography. Methods. The records of 230 breast cancer patients ( $n=125$ less than 40 and $n=105$ greater than 75 ) who presented to the Emory University Department of Radiation Oncology for curative treatment between 1997 and 2010 were reviewed. Data recorded included disease presentation, treatment, and areas of locoregional recurrence. Results. Women less than 40 years of age had higher rates of locoregional recurrence (20\% versus $7 \%, P=0.004)$ and distant recurrence $(18 \%$ versus $5 \%, P=0.003)$ than patients above 75 years of age. On multivariate analysis, patient age less than 40 was the only significant predictor of locoregional recurrence $(P=0.018)$. In a univariate analysis of each age group, receptor status and postlumpectomy radiation were significant predictors of locoregional recurrence-free survival in younger women while mammography screening predicted for distant recurrence-free survival in older patients. Conclusion. The factors identified in our age-stratified analysis highlight patients who are at high risk of locoregional and distant recurrence. Future studies aimed at enhancing therapies in young patients are warranted.
\end{abstract}

\section{Introduction}

Few studies have compared locoregional recurrence (LRR) and distant recurrence (DR) outcomes in women less than 40 with those above 75 years: two cohorts of women that are underrepresented in randomized trials of breast cancer treatments. Furthermore, these same groups of women fall outside breast cancer screening guidelines likely leading to underdetection of disease. Current mammography recommendations from the American Cancer Society (ACS) initiate screening at age of 40, and the US Preventive Task Force (USPTF) states that there is insufficient evidence to support screening mammograms in older women, particularly those above the age of 75 . However, patients under the age of 40 are more likely to be diagnosed with advanced stage disease and die more often due to their breast cancer [1]. Breast cancer in older women is generally thought to be relatively indolent [2], but some studies suggest that even older women may present with late-stage disease [3] and have poorer disease specific survival due to a lack of routine mammography screening [4].
Moreover, older women, unlike their younger counterparts, may have significant comorbidities that preclude standard therapeutic options and consequently adversely affect breast cancer specific outcomes.

LRR is correlated with increased risk for DR and poor survival outcomes [5]. One of the primary purposes of radiation following surgery is to reduce LRR rates and improve breast cancer specific survival and reduce the number of secondary surgeries and treatments. LRRs can occur in different tissue sites including the ipsilateral breast, chest wall, axillary, supraclavicular, and internal mammary lymph nodes. A local recurrence within the breast may require a complete mastectomy, as salvage treatment, while a chest wall recurrence may need excisional surgery along with radiation with or without systemic therapy [6]. Preventing a LRR is an important factor driving improvements in the treatment of primary breast tumors, but current guidelines for deciding lumpectomy versus mastectomy are based on potential cosmetic outcome, history of collagen vascular diseases and prior radiation, and patient and physician preference. The decision 
to treat with radiation is largely driven by type of surgery and presence of lymph node disease and positive margins. Whether to include the regional lymph nodes in the radiation fields is based on extent of lymph node involvement and initial size of the primary tumor. Few studies have examined whether young versus older patients have different patterns of LRR and whether patient age should be taken into account when determining surgery type and radiation treatment and field design.

Identifying risk factors contributing to locoregional recurrence-free survival (LRFS) and distant recurrence-free survival (DRFS) can help clinicians decide on appropriate treatments for patients in these age groups. Due to the importance of locoregional control in overall breast cancer prognosis, the aim of this study was to evaluate patterns and risk factors for LRFS and DRFS in patients younger than 40 and women older than 75, two understudied populations who are historically underrepresented in clinical trials and fall out of the range of screening guidelines.

\section{Materials and Methods}

The medical records of women evaluated for their breast cancer in Emory University Hospital's Department of Radiation Oncology from 1997 until 2010 were reviewed. Exclusion criteria included patient age between 40 and 74 years and stage IV or inflammatory breast cancer. In addition, among patients treated with chemotherapy, those who did not receive standard anthracycline or taxane-based treatments were excluded. In total, 230 women met eligibility criteria for this study with 125 patients below the age of 40 and 105 subjects above the age of 75 .

Tumor receptor status was determined by immunohistochemistry. Her-2-neu status was recorded as positive for tumors that stained $3+$ on immunohistochemistry. For Her2 -neu tumors that were $2+$, confirmatory fluorescence in situ hybridization (FISH) testing was performed. Tumors were staged according to the 2010 American Joint Committee on Cancer (AJCC) guidelines.

Outcomes included LRFS, DRFS, and overall survival (OS). LRR was defined as a biopsy proven recurrence of the primary breast cancer within the ipsilateral breast, chest wall, axillary, internal mammary, or supraclavicular lymph nodes. DR was defined as a biopsy proven recurrence in any other location of the body. Descriptive statistics were generated for all variables, summarized with frequencies and percentages. Covariates as well as predictors of LRFS, DRFS, and OS were compared across age groups using chi-squared tests or Fisher's exact tests, where appropriate. Univariate (UV) Cox proportional hazards models were fit for the outcomes listed above, using age as the primary predictor. Multivariate (MV) Cox models were fit for overall LRFS, DRFS, and OS. In addition, survival curves were generated for each outcome using the Kaplan-Meier method, stratified by age group. Outcomes such as 5-year survival rates were reported for each group, and differences in 5-year survival were compared using a $z$-test. Univariate analysis was performed to determine predictors of LRFS in each age cohort. Significance was assessed at the 0.05 level. Survival analysis was performed in SAS 9.3, and survival curves were generated in $R$. Firth's penalized maximum likelihood estimation was used in the survival models, in order to reduce bias in the parameter estimates and confidence intervals, as well as handle empty cells.

\section{Results}

3.1. Tumor Characteristics. The majority of younger women (88\%) presented with cancers that were symptomatic while the majority of older women $(63.1 \%)$ were more likely to have cancers detected by mammography $(P<0.001)$. Tumor grade and stage were also significantly different between the two groups. In the younger cohort, $55.9 \%$ of patients had grade 3 tumors compared to $32 \%$ of older patients $(P=$ 0.001 ). Clinical stage at presentation (young versus old) was Stage $0 / \mathrm{I}(21.0 \%$ versus $65.4 \%, P<0.001)$ and Stage II/III (79.0\% versus $34.6 \%, P<0.001)$. Additional information on tumor characteristics is available in Table 1.

3.2. Treatment Characteristics. A greater proportion of younger than older patients received chemotherapy. Chemotherapy was given in the neoadjuvant setting to $66.7 \%$ of younger patients versus $6.7 \%$ of older patients $(P<0.001)$. Chemotherapy was given in the adjuvant setting to $30.4 \%$ of younger patients and $9.52 \%$ of older patients $(P<0.001)$.

Lumpectomy was the most common surgical procedure in both groups of patients but the distribution of surgical procedures was significantly different between the age groups $(P<0.001)$. Surgical margins greater than 2 millimeters were achieved in $87.0 \%$ of younger women and in $77.5 \%$ of older women $(P=0.153)$. Approximately, $92.8 \%$ of younger patients versus $92.4 \%$ of older patients underwent postlumpectomy radiation, and $88.0 \%$ of younger patients versus $80.0 \%$ of older patients with lymph node positive disease underwent postmastectomy radiation. The differences were not statistically significant. Additional treatment characteristics are listed in Table 1.

3.3. Outcomes. The median follow-up period was 5.8 years (range from 1 month to 14.5 years) for both groups. LRFS rate was significantly lower in younger than older patients ( $84.5 \%$ versus $94.3 \%, P=0.023$ ) (see Figure 1 ). The DRFS rate was also significantly lower in younger women (83.1\% versus $95.5 \%, P=0.003$ ) (see Figure 2 ). OS was not significantly different between younger and older women at 5 years $(90 \%$ versus $88.3 \%, P=0.703$ ) (see Figure 3 ).

Age at diagnosis was associated with both LRFS and DRFS (HR: 3.1, 95\% CI: (1.3, 7.2), $P=0.006$; HR: 4.2, 95\% CI: $(1.6,11.0), P=0.002)$. Age remained significantly associated with LRFS in a multivariate model $(P=0.011)$. Grade was associated with overall survival in the UV model, while age was associated with overall survival in the MV model, adjusting for receptor status, grade, surgery type, and chemotherapy.

Among the 25 younger and 8 older patients who experienced a LRR, $64.0 \%$ of the younger patients recurred within 
TABLE 1: Breast cancer characteristics in younger and older women.

\begin{tabular}{|c|c|c|c|}
\hline Characteristic & $\begin{array}{l}\text { Age less than } 40 \\
N=125(\%)^{*}\end{array}$ & $\begin{array}{l}\text { Age greater than } 75 \\
\quad N=105(\%)^{*}\end{array}$ & $P$ value \\
\hline \multicolumn{4}{|l|}{ Receptor status } \\
\hline $\mathrm{ER} / \mathrm{PR}+^{\#}$ & $71(62.28)$ & $73(77.66)$ & \multirow{3}{*}{0.036} \\
\hline Her2+ & $11(9.65)$ & $8(8.51)$ & \\
\hline Triple negative & $32(28.07)$ & $13(13.83)$ & \\
\hline \multicolumn{4}{|l|}{ Grade } \\
\hline 1 & $14(12.61)$ & $26(26)$ & \multirow{3}{*}{0.001} \\
\hline 2 & $35(31.53)$ & $42(42)$ & \\
\hline 3 & $62(55.86)$ & $32(32)$ & \\
\hline \multicolumn{4}{|l|}{ Surgery type } \\
\hline Lumpectomy & $69(55.2)$ & $92(87.62)$ & \multirow{4}{*}{$<0.001$} \\
\hline Modified radical mastectomy & $20(16.0)$ & $9(8.57)$ & \\
\hline Simple mastectomy & $17(13.6)$ & $4(3.81)$ & \\
\hline Bilateral mastectomies & $19(15.2)$ & $0(0)$ & \\
\hline \multicolumn{4}{|l|}{ Adjuvant chemotherapy } \\
\hline No & $87(69.6)$ & $95(90.48)$ & \multirow{2}{*}{$<0.001$} \\
\hline Yes & $38(30.4)$ & $10(9.52)$ & \\
\hline \multicolumn{4}{|l|}{ Neoadjuvant chemotherapy } \\
\hline No & $41(32.8)$ & $98(93.33)$ & \multirow{2}{*}{$<0.001$} \\
\hline Yes & $84(67.2)$ & $7(6.67)$ & \\
\hline \multicolumn{4}{|l|}{ Detected on mammography } \\
\hline No & $103(88.03)$ & $38(36.89)$ & \multirow{2}{*}{$<0.001$} \\
\hline Yes & $14(11.97)$ & $65(63.11)$ & \\
\hline \multicolumn{4}{|l|}{ Stage at diagnosis } \\
\hline $0 / \mathrm{I}$ & $25(21.01)$ & $68(65.38)$ & \multirow{2}{*}{$<0.001$} \\
\hline II/III & $94(78.99)$ & $36(34.62)$ & \\
\hline \multicolumn{4}{|l|}{ Postmastectomy radiation } \\
\hline No & $16(28.57)$ & $3(23.08)$ & \multirow{2}{*}{1.000} \\
\hline Yes & $40(71.43)$ & $10(76.92)$ & \\
\hline \multicolumn{4}{|l|}{ Postlumpectomy radiation } \\
\hline No & $5(7.25)$ & $7(7.61)$ & \multirow[t]{2}{*}{0.931} \\
\hline Yes & $64(92.75)$ & $85(92.39)$ & \\
\hline \multicolumn{4}{|l|}{ Final margin status } \\
\hline Positive & $2(1.63)$ & $2(1.96)$ & \multirow{3}{*}{0.153} \\
\hline Less than $2 \mathrm{~mm}$ & $14(11.38)$ & $21(20.59)$ & \\
\hline Greater than $2 \mathrm{~mm}$ & $107(86.99)$ & $79(77.45)$ & \\
\hline
\end{tabular}

* Total patients for each characteristic may vary due to incomplete medical records for some patients.

${ }^{\#} \mathrm{ER} / \mathrm{PR}+$ : estrogen receptor/progesterone receptor positive.

breast/chest wall compared with $87.5 \%$ of older patients $(P=$ $0.387)$. In addition, $44 \%$ of younger patients recurred within the draining lymphatics compared with $29 \%$ of older patients $(P=0.671)$. Among the younger patients with lymphatic recurrence, $36 \%$ had level I or II axillary involvement, $18 \%$ had supraclavicular node (SCN) involvement, $27 \%$ had both axillary and SCN involvement, and 18\% had internal mammary node involvement. In older patients with a lymphatic recurrence, $50 \%$ had SCN involvement, 50\% had axillary and
SCN involvement, and none had internal mammary node involvement.

Univariate analysis was performed in each age group to determine if there were differences in predictors of LRFS and DRFS between groups. Among the younger patients, triple negative receptor status and lack of postlumpectomy radiation were significant predictors of lower LRFS (Table 2). Significant predictors for worse DRFS included mastectomy (as opposed to breast conserving surgery), use of adjuvant 


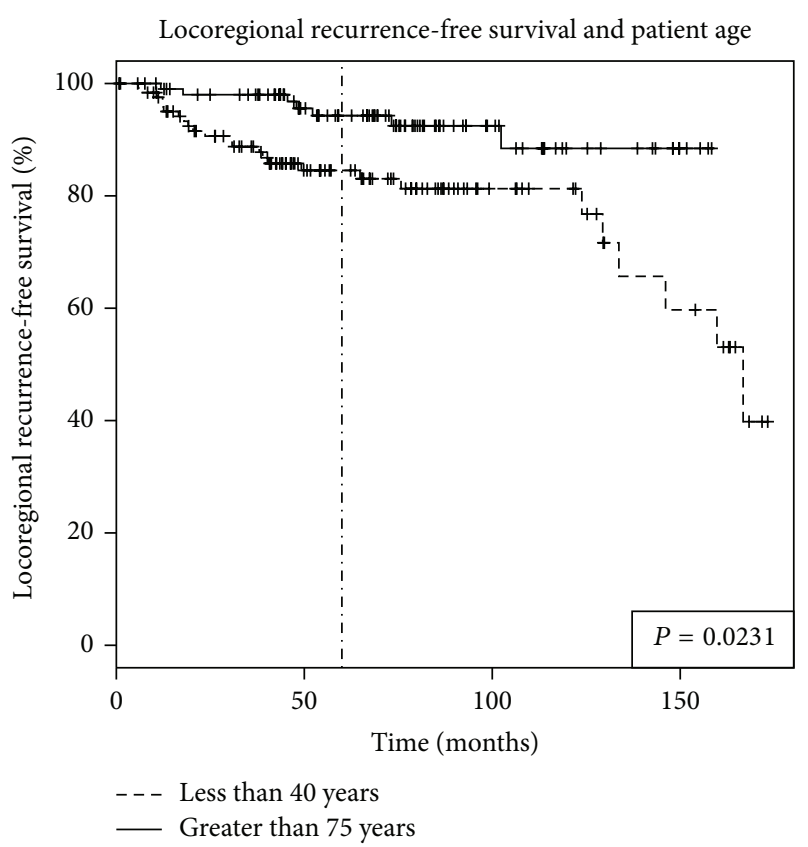

FIGURE 1: Locoregional recurrence-free survival (LRFS) in breast cancer patients based on patient age. Women younger than age of 40 had a significantly worse LRFS than those above the age of 75 . The 5-year rate of LRFS was $84.5 \%$ versus $94.3 \%(P=0.0231)$.

chemotherapy (significant log-rank $P$ value and marginally significant hazard ratio $P$ value), stage at diagnosis, nodal status, and use of postmastectomy radiation (Table 3). Among the older patients, there were no significant predictors for LRFS. Predictors of worse DRFS included type of surgery (i.e., mastectomy), use of neoadjuvant chemotherapy, lack of mammography screening (significant log-rank $P$ value and marginally significant hazard ratio $P$ value), and positive nodal status (significant log-rank $P$ value and marginally significant hazard ratio $P$ value) (Table 4 ). The small number of events in each age group precluded meaningful MV analysis.

\section{Discussion}

This study revealed that age at diagnosis is a strong predictor for LRFS and DRFS. Younger patients developed both types of recurrence more frequently than their older counterparts. Since these events carry poor prognoses for survival outcomes, it was necessary to identify appropriate risk factors in these understudied populations.

The tumor characteristics of our study are consistent with previous studies which indicate that younger patients tend to present with tumors that are self-detected rather than detected by screening mammography. Indeed, other studies have confirmed that young women with breast cancer are most likely to present with symptomatic, large palpable masses [1] in part due to lack of screening in this patient population. These tumors are generally poorly differentiated, higher grade and are associated with lymphovascular invasion [1-4]. Our results support these findings, as younger

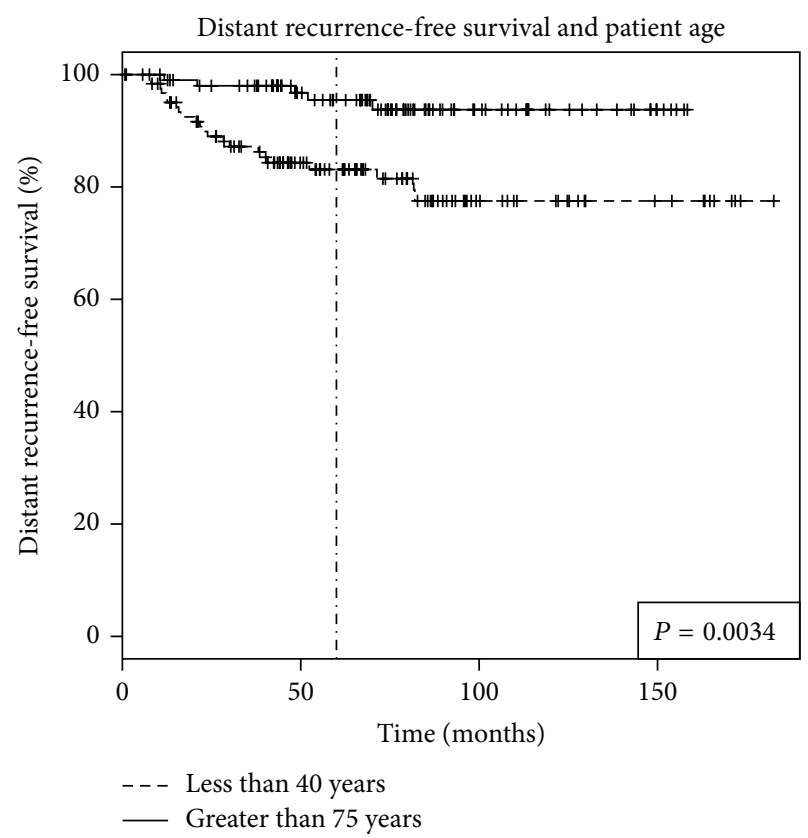

FIGURE 2: Distant recurrence-free survival (DRFS) in breast cancer patients based on patient age. Women younger than age of 40 had a significantly worse DRFS than those above the age of 75 . The 5-year rate of DRFS was $83.1 \%$ versus $95.5 \%(P=0.0034)$.

women presenting to our department for radiation tended to present with advanced stage disease as well. Furthermore, more advanced stage and higher grade tumors in young women have been linked with LRR in the literature [7].

Unlike the younger women in our study, the older women were diagnosed with smaller and lower grade tumors. Most of these tumors were discovered on screening mammography despite the lack of clear guidelines for this age group. In addition, studies of older women have generally reported favorable tumor characteristics $[8,9]$. However, in one retrospective review of 135 women with a median age of 83 years, $59 \%$ of tumors were histological grade 2-3 with lymph node involvement [10]. In general, the favorable tumor characteristics in patients above 75 years of age contributed to lower LRR rates in our study.

Systemic chemotherapy and/or targeted agents were used on younger women more often than women above the age of 75 partly due to the higher stage at presentation. Systemic treatment recommendations for breast cancer are based on perceived benefits and potential toxicities such that decisions are often made based on age, cancer stage, patient performance status, and comorbidities. Fewer elderly women receive chemotherapy for their breast cancer [11, 12], and when they are prescribed systemic therapy, they are often given noncardiotoxic agents [13]. However, even with the use of chemotherapy, recurrence rates were significantly higher in the younger cohort due to the advanced stage at presentation.

In support of our findings, others have shown that breast cancer tends to recur at a higher rate in younger women $[1,3]$. In an age-specific analysis of clinical outcomes, Anders et al. reported inferior disease-free survival (DFS) in women 
TABLE 2: Univariate analysis of risk factors for locoregional free survival in younger women.

\begin{tabular}{|c|c|c|c|c|}
\hline Characteristic & $N(\%)^{*}$ & $\begin{array}{c}\text { Hazard ratio } \\
(95 \% \mathrm{CI})\end{array}$ & $\begin{array}{c}\text { Hazard ratio } \\
P \text { value }\end{array}$ & $\begin{array}{c}\text { Log-rank } \\
P \text { value }\end{array}$ \\
\hline \multicolumn{5}{|l|}{ Receptor status } \\
\hline $\mathrm{ER} / \mathrm{PR}+^{\#}$ & $71(62.28)$ & $0.35(0.15-0.85)$ & 0.021 & \multirow{3}{*}{0.033} \\
\hline Her2+ & $11(9.65)$ & $0.34(0.06-1.99)$ & 0.231 & \\
\hline Triple negative & $32(28.07)$ & - & & \\
\hline \multicolumn{5}{|l|}{ Grade } \\
\hline 1 & $14(12.61)$ & $1.11(0.36-3.42)$ & 0.854 & \multirow{3}{*}{0.949} \\
\hline 2 & $35(31.53)$ & $0.90(0.34-2.40)$ & 0.832 & \\
\hline 3 & $62(55.86)$ & - & & \\
\hline \multicolumn{5}{|l|}{ Surgery type } \\
\hline Lumpectomy & $69(55.2)$ & $1.20(0.52-2.73)$ & 0.672 & \multirow{2}{*}{0.634} \\
\hline Mastectomy & $56(44.8)$ & - & & \\
\hline \multicolumn{5}{|c|}{ Adjuvant chemotherapy } \\
\hline No & $87(69.6)$ & $0.87(0.38-1.99)$ & 0.736 & \multirow{2}{*}{0.781} \\
\hline Yes & $38(30.4)$ & - & & \\
\hline \multicolumn{5}{|c|}{ Neoadjuvant chemotherapy } \\
\hline No & $41(32.8)$ & $1.83(0.82-4.07)$ & 0.137 & \multirow{2}{*}{0.134} \\
\hline Yes & $84(67.2)$ & - & & \\
\hline \multicolumn{5}{|c|}{ Detected on mammography } \\
\hline No & $103(88.03)$ & $0.40(0.15-1.05)$ & 0.062 & \multirow{2}{*}{0.075} \\
\hline Yes & $14(11.97)$ & - & & \\
\hline \multicolumn{5}{|l|}{ Stage at diagnosis } \\
\hline $0 / \mathrm{I}$ & $25(21.01)$ & $2.02(0.85-4.79)$ & 0.111 & \multirow{2}{*}{0.120} \\
\hline II/III & $94(78.99)$ & - & & \\
\hline \multicolumn{5}{|l|}{ Nodal status } \\
\hline Positive & $41(32.8)$ & $0.78(0.33-1.85)$ & 0.572 & \multirow{2}{*}{0.512} \\
\hline Negative & $84(67.2)$ & - & & \\
\hline \multicolumn{5}{|c|}{ Postmastectomy radiation } \\
\hline No & $16(28.57)$ & $1.18(0.30-4.66)$ & 0.816 & \multirow{2}{*}{0.901} \\
\hline Yes & $40(71.43)$ & - & & \\
\hline \multicolumn{5}{|c|}{ Postlumpectomy radiation } \\
\hline No & $5(7.25)$ & $6.34(1.46-27.55)$ & 0.014 & \multirow[b]{2}{*}{0.017} \\
\hline Yes & $64(92.75)$ & - & & \\
\hline \multicolumn{5}{|l|}{ Final margin status } \\
\hline Positive & $(1.63)$ & $1.92(0.10-36.83)$ & 0.665 & \multirow{3}{*}{0.774} \\
\hline Less than $2 \mathrm{~mm}$ & $14(11.38)$ & $1.55(0.47-5.09)$ & 0.474 & \\
\hline Greater than $2 \mathrm{~mm}$ & $107(86.99)$ & - & & \\
\hline
\end{tabular}

* Total patients for each characteristic may vary due to incomplete medical records for some patients.

${ }^{\#} \mathrm{ER} / \mathrm{PR}+$ : estrogen receptor/progesterone receptor positive.

less than 45 as compared with those greater than 65 years, with the lowest DFS in women less than 40 years of age [14]. The younger patients in our study showed significantly worse LRFS and DRFS outcomes when compared with older patients, but only LRFS remained significantly associated with age in the MV model.

In an age-stratified analysis, we attempted to identify predictors for LRFS and DRFS in each age group. For younger patients, receptor status was associated with LRFS.
In particular, triple negative receptor status had the strongest association with locoregional failure. Our study suggested that triple negative breast cancer (TNBC) patients should receive more aggressive treatment and surveillance recommendations in order to achieve better local control. Another predictor of worse LRFS in young patients was lack of postlumpectomy radiation. In a study by Dragun et al, TNBC patients who did not receive radiation had a higher risk of LRR despite lower staging at diagnosis [15]. After 
TABLE 3: Univariate analysis of risk factors for distant recurrence-free survival in younger women.

\begin{tabular}{|c|c|c|c|c|}
\hline Characteristic & $N^{*}$ & $\begin{array}{c}\text { Hazard ratio } \\
(95 \% \mathrm{CI})\end{array}$ & $\begin{array}{c}\text { HR } \\
P \text { value }\end{array}$ & $\begin{array}{c}\text { Log-rank } \\
P \text { value }\end{array}$ \\
\hline \multicolumn{5}{|l|}{ Receptor status } \\
\hline $\mathrm{ER} / \mathrm{PR}+^{\#}$ & $71(62.28)$ & $0.87(0.33-2.31)$ & 0.786 & \multirow{3}{*}{0.822} \\
\hline Her2+ & $11(9.65)$ & $0.71(0.11-4.48)$ & 0.716 & \\
\hline Triple negative & $32(28.07)$ & - & & \\
\hline \multicolumn{5}{|l|}{ Grade } \\
\hline 1 & $14(12.61)$ & $0.80(0.19-3.36)$ & 0.766 & \multirow{3}{*}{0.818} \\
\hline 2 & $35(31.53)$ & $0.82(0.28-2.35)$ & 0.706 & \\
\hline 3 & $62(55.86)$ & - & & \\
\hline \multicolumn{5}{|l|}{ Surgery type } \\
\hline Lumpectomy & $69(55.2)$ & $0.28(0.11-0.72)$ & 0.008 & \multirow{2}{*}{0.003} \\
\hline Mastectomy & $56(44.8)$ & - & & \\
\hline \multicolumn{5}{|l|}{ Adjuvant chemotherapy } \\
\hline No & $87(69.6)$ & $0.40(0.17-0.93)$ & 0.033 & \multirow{2}{*}{0.027} \\
\hline Yes & $38(30.4)$ & - & & \\
\hline \multicolumn{5}{|c|}{ Neoadjuvant chemotherapy } \\
\hline No & $41(32.8)$ & $0.89(0.35-2.26)$ & 0.812 & \multirow{2}{*}{0.735} \\
\hline Yes & $84(67.2)$ & - & & \\
\hline \multicolumn{5}{|c|}{ Detected on mammography } \\
\hline No & $103(88.03)$ & $1.10(0.29-4.25)$ & 0.888 & \multirow{2}{*}{0.692} \\
\hline & $14(11.97)$ & - & & \\
\hline \multicolumn{5}{|l|}{ Stage at diagnosis } \\
\hline $0 / \mathrm{I}$ & $25(21.01)$ & $0.09(0.00-1.55)$ & 0.097 & \multirow{2}{*}{0.018} \\
\hline II/III & $94(78.99)$ & - & & \\
\hline \multicolumn{5}{|l|}{ Nodal status } \\
\hline Positive & $41(32.8)$ & $2.58(1.12-5.98)$ & 0.027 & \multirow{2}{*}{0.020} \\
\hline Negative & $84(67.2)$ & - & & \\
\hline \multicolumn{5}{|c|}{ Postmastectomy radiation } \\
\hline No & $16(28.57)$ & $0.17(0.03-0.98)$ & 0.048 & \multirow{2}{*}{0.014} \\
\hline Yes & $40(71.43)$ & - & & \\
\hline \multicolumn{5}{|c|}{ Postlumpectomy radiation } \\
\hline No & $5(7.25)$ & $1.19(0.05-26.66)$ & 0.912 & \multirow{2}{*}{0.534} \\
\hline Yes & $64(92.75)$ & - & & \\
\hline \multicolumn{5}{|l|}{ Final margin status } \\
\hline Positive & $2(1.63)$ & $1.47(0.08-27.41)$ & 0.795 & \multirow{3}{*}{0.771} \\
\hline Less than $2 \mathrm{~mm}$ & $14(11.38)$ & $0.88(0.23-3.41)$ & 0.851 & \\
\hline Greater than $2 \mathrm{~mm}$ & $107(86.99)$ & - & & \\
\hline
\end{tabular}

${ }^{*}$ Total patients for each characteristic may vary due to incomplete medical records for some patients.

${ }^{\#} \mathrm{ER} / \mathrm{PR}+$ : estrogen receptor/progesterone receptor positive.

recognizing the high potential of $L R R$ in triple negative cancers, the authors proposed strongly considering radiation in nontraditional patients such as "postmastectomy patients with $<4$ positive lymph nodes and/or tumors $<5 \mathrm{~cm}$ in size" [15]. In our study, the younger patients also tended to recur in the regional nodal regions more than older patients. This data suggests that when young breast cancer patients are prescribed radiation, they may benefit from regional nodal radiation in addition to breast or chest wall treatment.

Among our patients, worse DRFS in young patients was predicted by multiple factors including stage at diagnosis, presence of nodal disease, mastectomy, use of adjuvant chemotherapy, and use of postmastectomy radiation. The worse outcomes associated with these breast cancer treatments are likely due to the initial advanced disease presentations of these patients. Given our results, future research should be devoted to improving screening techniques and guidelines to prevent advanced disease presentations in young patients.

The stratified analysis did not identify any risk factors for LRFS in the older cohort. However, worse DRFS was associated with positive nodal status, mastectomy, use of neoadjuvant chemotherapy, and lack of mammography screening. Although the older patients had significantly lower LRFS and DRFS rates, they did not have significantly better OS at 5 years. This is likely due to comorbidities unrelated to breast cancer. A recent SEER database study of approximately 64,000 women diagnosed with breast cancer at age of 66 and older found that elderly women with breast cancer were just as likely to die of cardiovascular disease as they were of their breast cancer [16]. The degree to which undertreatment impacts breast cancer outcomes in older women remains an 
TABLE 4: Univariate analysis of risk factors for distant recurrence-free survival in older women.

\begin{tabular}{|c|c|c|c|c|}
\hline Characteristic & $N^{*}$ & $\begin{array}{c}\text { Hazard ratio } \\
(95 \% \mathrm{CI})\end{array}$ & $\begin{array}{c}\text { HR } \\
P \text { value }\end{array}$ & $\begin{array}{c}\text { Log-rank } \\
P \text { value }\end{array}$ \\
\hline \multicolumn{5}{|l|}{ Receptor status } \\
\hline $\mathrm{ER} / \mathrm{PR}+^{\#}$ & $73(77.66)$ & $0.51(0.06-4.19)$ & 0.530 & \multirow{3}{*}{0.732} \\
\hline Her2+ & $8(8.51)$ & $0.49(0.01-19.06)$ & 0.706 & \\
\hline Triple negative & $13(13.83)$ & - & & \\
\hline \multicolumn{5}{|l|}{ Grade } \\
\hline 1 & $26(26)$ & $0.20(0.01-6.55)$ & 0.370 & \multirow{3}{*}{0.339} \\
\hline 2 & $42(42)$ & $1.08(0.17-6.88)$ & 0.935 & \\
\hline 3 & $32(32)$ & - & & \\
\hline \multicolumn{5}{|l|}{ Surgery type } \\
\hline Lumpectomy & $92(87.6)$ & $0.06(0.01-0.36)$ & 0.002 & \multirow{2}{*}{$<0.001$} \\
\hline Mastectomy & $13(12.4)$ & - & & \\
\hline \multicolumn{5}{|c|}{ Adjuvant chemotherapy } \\
\hline No & $95(90.48)$ & $0.33(0.04-2.50)$ & 0.282 & \multirow{2}{*}{0.447} \\
\hline Yes & $10(9.52)$ & - & & \\
\hline \multicolumn{5}{|c|}{ Neoadjuvant chemotherapy } \\
\hline No & $98(93.33)$ & $0.03(0.00-0.27)$ & 0.001 & \multirow{2}{*}{$<0.001$} \\
\hline Yes & $7(6.67)$ & - & & \\
\hline \multicolumn{5}{|c|}{ Detected on mammography } \\
\hline No & $38(36.89)$ & $6.44(0.84-49.11)$ & 0.073 & \multirow{2}{*}{0.022} \\
\hline Yes & $65(63.11)$ & - & & \\
\hline \multicolumn{5}{|l|}{ Stage at diagnosis } \\
\hline $0 / \mathrm{I}$ & $68(65.38)$ & $0.34(0.06-2.02)$ & 0.237 & \multirow{2}{*}{0.187} \\
\hline II/III & $36(34.62)$ & - & & \\
\hline \multicolumn{5}{|l|}{ Nodal status } \\
\hline Positive & $24(22.86)$ & $4.77(0.81-28.25)$ & 0.085 & \multirow{2}{*}{0.046} \\
\hline Negative & $81(77.14)$ & - & & \\
\hline \multicolumn{5}{|c|}{ Postmastectomy radiation } \\
\hline No & $3(23.08)$ & $2.96(0.27-32.47)$ & 0.374 & \multirow{2}{*}{0.454} \\
\hline Yes & $10(76.92)$ & - & & \\
\hline \multicolumn{5}{|c|}{ Postlumpectomy radiation } \\
\hline No & $7(7.61)$ & $3.42(0.08-141.16)$ & 0.517 & \multirow{2}{*}{0.733} \\
\hline Yes & $85(92.39)$ & - & & \\
\hline \multicolumn{5}{|l|}{ Final margin status } \\
\hline Positive & $2(1.96)$ & $4.19(0.15-115.22)$ & 0.397 & \multirow{3}{*}{0.549} \\
\hline Less than $2 \mathrm{~mm}$ & $21(20.59)$ & $0.42(0.02-11.35)$ & 0.603 & \\
\hline Greater than $2 \mathrm{~mm}$ & $79(77.45)$ & - & & \\
\hline
\end{tabular}

* Total patients for each characteristic may vary due to incomplete medical records for some patients.

${ }^{\#} \mathrm{ER} / \mathrm{PR}+$ : estrogen receptor/progesterone receptor positive.

area of current debate. Gajdos et al. compared 206 women whose ages are 70 and over and compared them with 920 younger women and found that $54 \%$ of the elderly group were undertreated; however, local and distant recurrence-free survival rates were comparable among the two cohorts of patients regardless of treatment [17]. These data strongly suggest that older women tend to die of non-breast cancer related causes in spite of less aggressive and nonstandard therapy for their breast cancer. Yet, one recent retrospective analysis of postmenopausal patients with early stage breast cancer who participated in the Tamoxifen Exemestane Adjuvant Multinational (TEAM) trial found that higher breast cancerspecific mortality with increasing age may be attributed to undertreatment [18]. In addition, Schonberg et al. report that patients who are 67 years or older with stage II or higher disease had increased mortality when compared with similarly aged patients without breast cancer [19]. While such studies call for aggressive standard treatment in older 


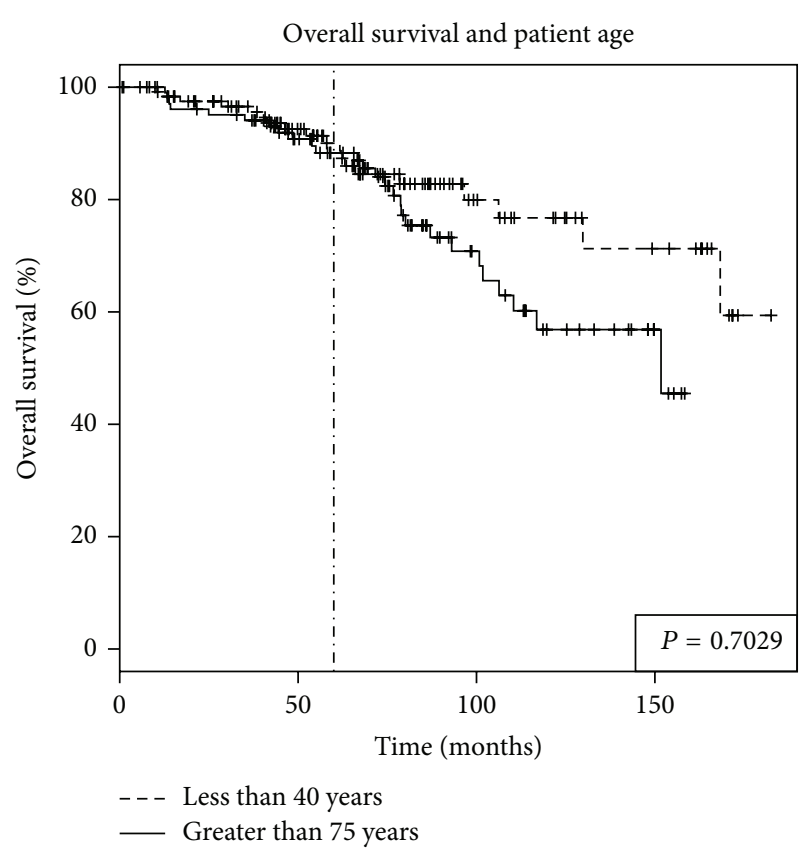

Figure 3: Overall survival (OS) in breast cancer patients based on patient age. Women younger than age of 40 and women older than age of 75 did not have significantly different OS. The 5-year rate of OS was $90 \%$ versus $88.3 \%(P=0.7029)$.

women, our study suggests that older women who are healthy enough candidates to be considered for radiation still tend to die of causes unrelated to their breast cancer irrespective of treatment.

The risk factors for locoregional and distant recurrences suggested by this study were developed through a retrospective method and the findings are therefore hypothesis generating. A prospective study must further evaluate these risk factors in order to establish the proper associations.

\section{Conclusion}

Women less than 40 years old suffer significantly worse LRFS and DRFS in spite of aggressive therapies. This is likely due to the combination of aggressive breast tumor characteristics and inadequate screening. In contrast, less aggressive treatment in older women with early stage tumors does not appear to affect their overall breast cancer outcomes. Future studies aimed at assessing biological risk factors for breast cancer are warranted independent of age. Such information could be used to more effectively detect breast cancer and potentially administer treatment in women not typically screened with mammography.

\section{Disclaimer}

The content is solely the responsibility of the authors and does not necessarily represent the official views of the National Institutes of Health

\section{Conflict of Interests}

The authors declare that there is no conflict of interests regarding the publication of this paper.

\section{Acknowledgment}

Research reported in this paper was supported in part by the Biostatistics and Bioinformatics Shared Resource of the Winship Cancer Institute of Emory University and NIH/NCI under Award no. P30CA138292.

\section{References}

[1] C. Gajdos, P. I. Tartter, I. J. Bleiweiss, C. Bodian, and S. T. Brower, "Stage 0 to stage III breast cancer in young women," Journal of the American College of Surgeons, vol. 190, no. 5, pp. 523-529, 2000.

[2] D. Axelrod, J. Smith, D. Kornreich et al., "Breast Cancer in Young Women," Journal of the American College of Surgeons, vol. 206, no. 6, pp. 1193-1203, 2008.

[3] J. Kollias, C. W. Elston, I. O. Ellis, J. F. R. Robertson, and R. W. Blamey, "Early-onset breast cancer-histopathological and prognostic considerations," British Journal of Cancer, vol. 75, no. 9, pp. 1318-1323, 1997.

[4] J. L. Gnerlich, A. D. Deshpande, D. B. Jeffe, A. Sweet, N. White, and J. A. Margenthaler, "Elevated breast cancer mortality in women younger than age 40 years compared with older women is attributed to poorer survival in early-stage disease," Journal of the American College of Surgeons, vol. 208, no. 3, pp. 341-347, 2009.

[5] S. J. Anderson, I. Wapnir, J. J. Dignam et al., "Prognosis after ipsilateral breast tumor recurrence and locoregional recurrences in patients treated by breast-conserving therapy in five national surgical adjuvant breast and bowel project protocols of node-negative breast cancer," Journal of Clinical Oncology, vol. 27, no. 15, pp. 2466-2473, 2009.

[6] N. Shikama, K. Sekiguchi, and N. Nakamura, "Management of locoregional recurrence of breast cancer," Breast Cancer, vol. 18, no. 4, pp. 252-258, 2011.

[7] A. Wallgren, M. Bonetti, R. D. Gelber et al., "Risk factors for locoregional recurrence among breast cancer patients: results from International Breast Cancer Study Group Trials I through VII," Journal of Clinical Oncology, vol. 21, no. 7, pp. 1205-1213, 2003.

[8] R. Gennari, G. Curigliano, N. Rotmensz et al., "Breast carcinoma in elderly women: features of disease presentation, choice of local and systemic treatments compared with younger postmenopausal patients," Cancer, vol. 101, no. 6, pp. 1302-1310, 2004.

[9] A. Cyr, W. E. Gillanders, R. L. Aft, T. J. Eberlein, and J. A. Margenthaler, "Breast cancer in elderly women ( $\geq 80$ years): variation in standard of care?" Journal of Surgical Oncology, vol. 103, no. 3, pp. 201-206, 2011.

[10] E. Evron, H. Goldberg, A. Kuzmin et al., "Breast cancer in octogenarians," Cancer, vol. 106, no. 8, pp. 1664-1668, 2006.

[11] A. Brunello, U. Basso, C. Pogliani et al., "Adjuvant chemotherapy for elderly patients ( $\geq 70$ years) with early high-risk breast cancer: a retrospective analysis of 260 patients," Annals of Oncology, vol. 16, no. 8, pp. 1276-1282, 2005. 
[12] S. H. Giordano, G. N. Hortobagyi, S.-W. C. Kau, R. L. Theriault, and M. L. Bondy, "Breast cancer treatment guidelines in older women," Journal of Clinical Oncology, vol. 23, no. 4, pp. 783-791, 2005.

[13] G. H. Lyman, D. C. Dale, and J. Crawford, "Incidence and predictors of low dose-intensity in adjuvant breast cancer chemotherapy: a nationwide study of community practices," Journal of Clinical Oncology, vol. 21, no. 24, pp. 4524-4531, 2003.

[14] C. K. Anders, D. S. Hsu, G. Broadwater et al., "Young age at diagnosis correlates with worse prognosis and defines a subset of breast cancers with shared patterns of gene expression," Journal of Clinical Oncology, vol. 26, no. 20, pp. 3324-3330, 2008.

[15] A. E. Dragun, J. Pan, S. N. Rai, B. Kruse, and D. Jain, "Locoregional recurrence in patients with triple-negative breast cancer: preliminary results of a single institution study," The American Journal of Clinical Oncology, vol. 34, no. 3, pp. 231237, 2011.

[16] J. L. Patnaik, T. Byers, C. DiGuiseppi, D. Dabelea, and T. D. Denberg, "Cardiovascular disease competes with breast cancer as the leading cause of death for older females diagnosed with breast cancer: a retrospective cohort study," Breast Cancer Research, vol. 13, no. 3, article R64, 2011.

[17] C. Gajdos, P. I. Tartter, I. J. Bleiweiss, R. A. Lopchinsky, and J. L. Bernstein, "The consequence of undertreating breast cancer in the elderly," Journal of the American College of Surgeons, vol. 192, no. 6, pp. 698-707, 2001.

[18] W. van de Water, C. Markopoulos, C. J. H. van de Velde et al., "Association between age at diagnosis and diseasespecific mortality among postmenopausal women with hormone receptor-positive breast cancer," Journal of the American Medical Association, vol. 307, no. 6, pp. 590-597, 2012.

[19] M. A. Schonberg, E. R. Marcantonio, L. Ngo, D. Li, R. A. Silliman, and E. P. McCarthy, "Causes of death and relative survival of older women after a breast cancer diagnosis," Journal of Clinical Oncology, vol. 29, no. 12, pp. 1570-1577, 2011. 


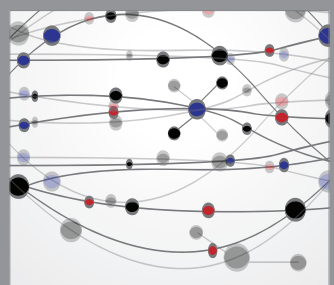

The Scientific World Journal
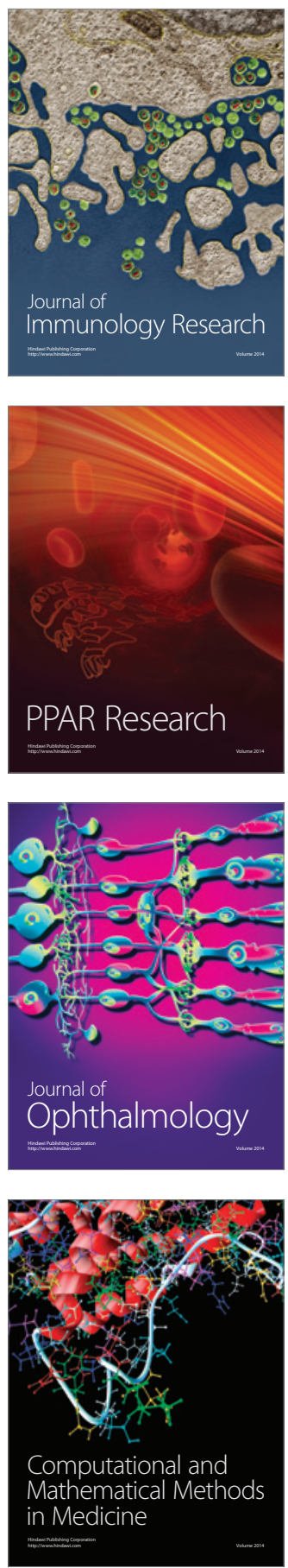

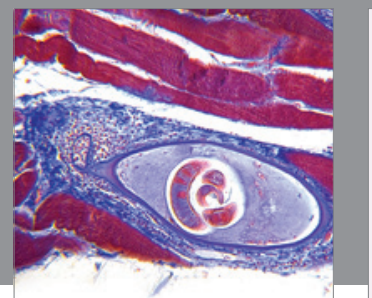

Gastroenterology

Research and Practice
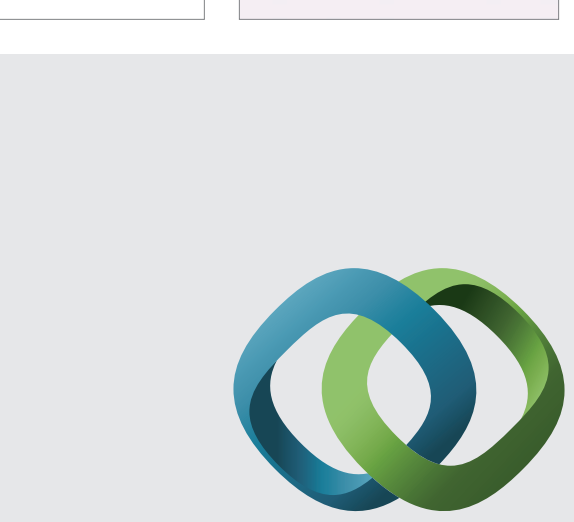

\section{Hindawi}

Submit your manuscripts at

http://www.hindawi.com
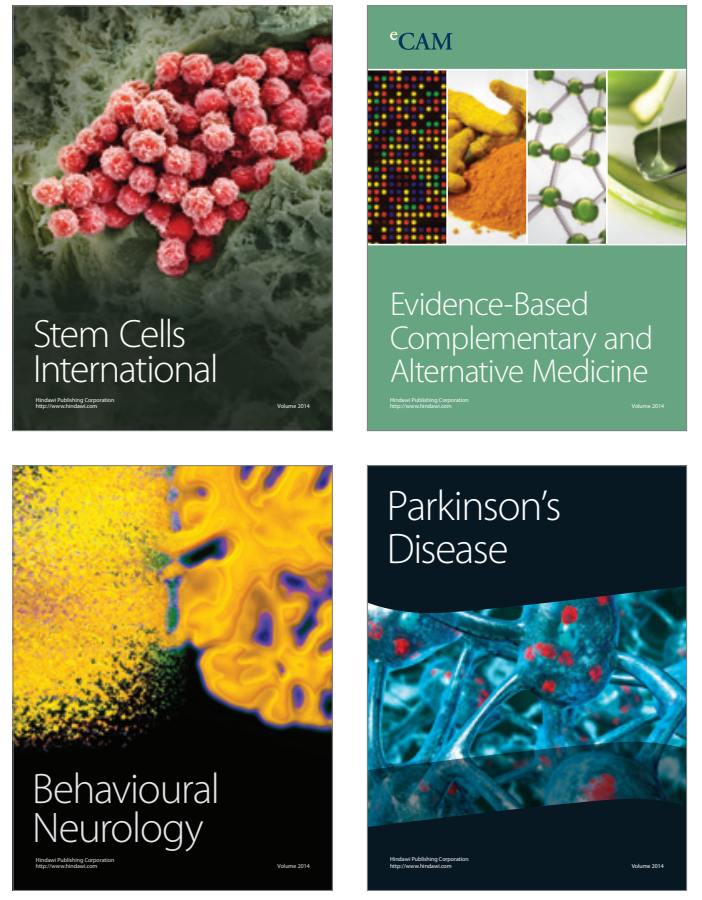
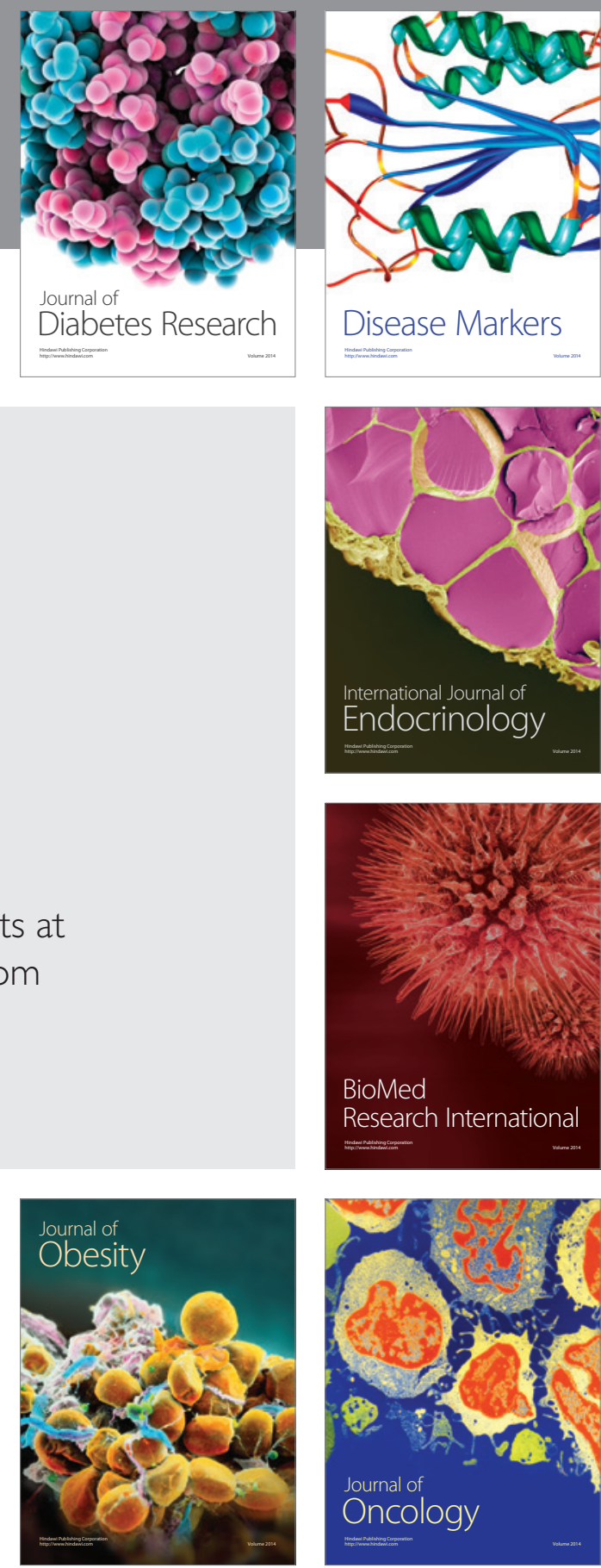

Disease Markers
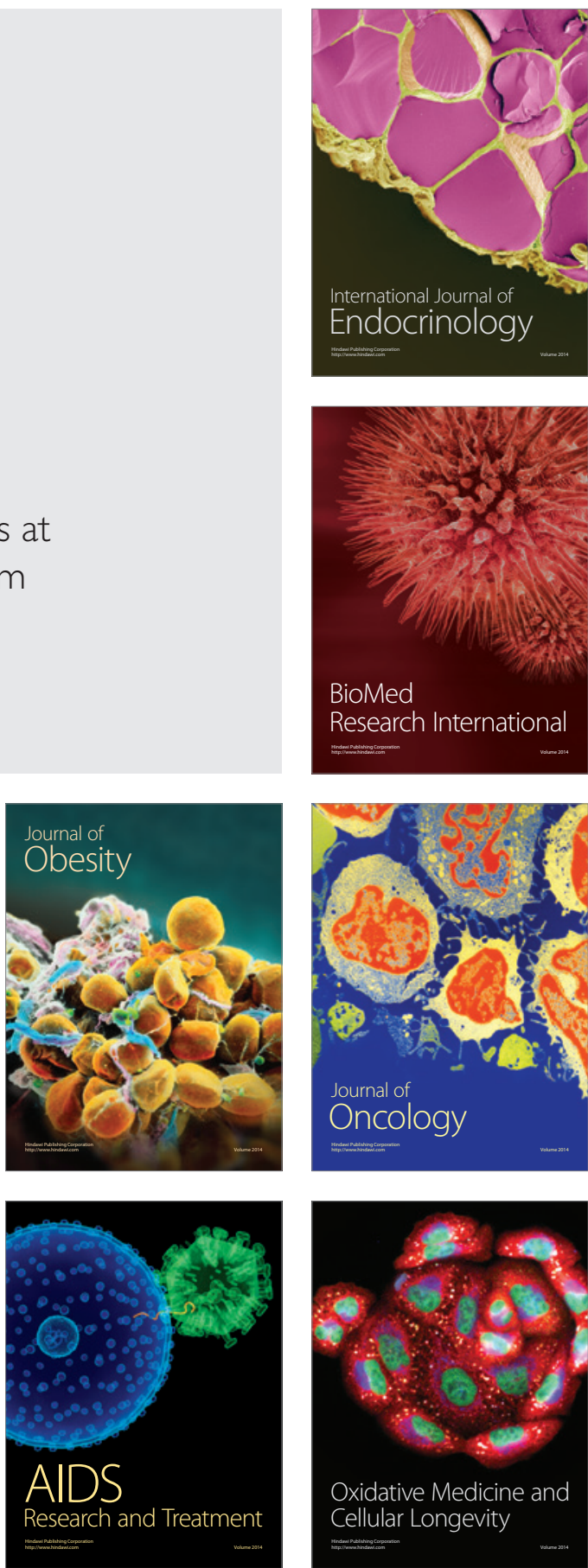